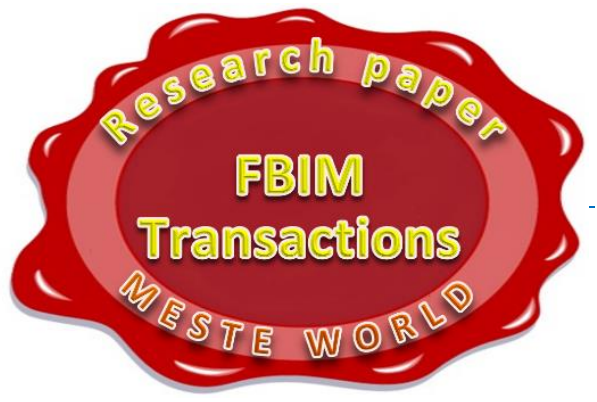

\title{
THE ALIGNMENT OF THE
}

\section{ORGANIZATIONAL BUSINESS STRATEGY} AND PROJECT MANAGEMENT METHODS

\section{Sonja Gegovska-Zajkova}

Ss Cyril and Methodius University, Faculty of Electrical Engineering and Information Technologies, Skopje, Republic of Macedonia

\section{Nevenka Kiteva Rogleva}

Ss Cyril and Methodius University, Faculty of Electrical Engineering and Information Technologies, Skopje, Republic of Macedonia

\section{Vangel Fustic}

Ss Cyril and Methodius University, Faculty of Electrical Engineering and Information Technologies, Skopje, Republic of Macedonia

\section{(C) MESTE NGO}

JEL category: L1, M11

\begin{abstract}
The paper deals with one of the most important issues of the organizational business strategy in companies in developing countries, running their businesses in the age of "New Economy". The alignment of the project management methodologies, tools and techniques with company's strategy is one of highest priorities for top managers and their decisions. The survey and the analysis of the results create a basis for an insight into the conditions that are present in our practice, concerning application of the project management methodologies, especially using ICT in conducting their businesses in a sensitive economic environment, as it is in developing countries. The results of the study may help companies for appropriate business strategy development in the new business and market environment.
\end{abstract}

Keywords: business strategy, project management methodologies, industry survey, new economy, ICT

\section{INTRODUCTION}

The most important task in every company is business development along with a proper organizational strategy. It is necessary to take the

Address of the corresponding author:

Sonja Gegovska-Zajkova

䤵="szajkova@feit.ukim.edu.mk lead in realizing that strategy vision, which means that it has to be implemented and tested to prove that it leads the company to success. This requires innovation, constantly following new trends and technologies and application of methods and tools of the project management.

Company's strategy should correspond to the business area in which a company wants to 
achieve its business needs. It should also be viable for that particular business in last decade when a New Economy is increasingly accomplished through projects (Grant, 2002).

As a result of such trend, it is obvious that today, the company business strategy is mostly affected by the projects. It means that the company has to adapt itself to the new project oriented business environment. The alignment of the undertaken projects and their methods with the company's business strategy is the essential factor for the success, also.

However, it is very important to understand the business needs and the business strategy of the company and how to realize those needs, as well as how to accomplish the strategy. This is a way to attain an important and necessary competitive advantage, which could result in business success. The knowledge necessary for realizing company's projects is basis for achieving competitive advantage in the new business and economic environment.

For better business strategy fulfillment, some organizations have already implemented Information and Communication Technologies (ICT) systems. The use of ICT systems requires a good perception of the business environment, as well as the market opportunities. Good analysis is essential to find the best and most appropriate solution among all offered in the market. Success could be achieved through development activities, starting with a good analysis, development and finally implementation and evaluation of the solution.

It is, therefore, necessary to apply Project management and its methods and techniques. Project management, as a basis for successful implementation of the project, includes detailed planning of the activities that creates the conditions for success and strategy implementation, leadership, business processes and goals, skills, systems and risks. Thus, it organizes the system's work in the project.

It is generally accepted misconception that techniques of project management are procedures that are easy to learn and implement. But does it work in some developing countries with lack of Project management knowledge and skills?

This paper summarizes the results of a survey concerning the implementation of project management methods, tools and techniques conducted on various companies in the Republic of Macedonia. Data sets for statistical analysis were collected using an originally created questionnaire. One of the critical criteria analyzed by the client questionnaire was client satisfaction.

To achieve this goal, in Section 2 of this paper there is a brief overview of the most commonly used project management methodologies. The research methodologies adopted in this study are described in Section 3. In Section 4 there is analysis with a focus on the survey results, and, finally in Section 5, conclusions and remarks are provided.

\section{PROJECT METHODOLOGIES}

There are many different project management methodologies and techniques. Here, we highlight the most commonly used methodologies: Agile, Crystal, Waterfall, PRINCE2 and RUP, emphasizing their advantages and disadvantages.

Agile methodology is based on short iteration cycles, which allows better respond to changes in business environment. One of the key principles in Agile development is to avoid unnecessary bureaucracy and documentation. When implementing Agile methods, the role of the team often takes central stage. Agile also means: more learner control, team responsibility, empowerment of the project officers. The project leader in an Agile environment focuses mainly on coaching and encouraging leadership. Project officers with insufficient seniority or lack of responsibility that cannot handle this freedom, cannot participate in an Agile environment (Dijk, 2009).

In other words, the Agile method means that a project is delivered at agreed times in small complete parts useful for the customer. The advantage of delivery in parts is an opportunity of sooner receiving feedback that can be used for the next parts. It requires the appropriate information system, which can be delivered in small complete parts. At the start of the project, the requirements 
do not need to be known entirely and in detail. This enables starting with a project whilst not all requirements are known at detailed level. In the Agile working method, it is of vital importance for everything delivered to be of extremely high quality. When constantly iterating, one wants to be able to trust everything that is finished. The products of an Agile project will also be taken into production, so there is a need for various types of documentation.

Crystal is a family of Agile software development methodology (Cockburn, 2004). The starting point is the fact that the projects properties change depending on the number of people involved and the criticality of the project, ranging from loss of money to loss of life.

Crystal introduces the importance of people and communications, and adjusting the techniques used in a project to the characteristics of that particular project. While other software development methods, particularly other Agile methods, do stress the importance of people, the Crystal family uses a focus on people and communications as its organizing principle, and most of the properties and techniques are based on strengthening that process.

Crystal Clear is part of Crystal family of methodologies, where every methodology is characterized by a color. That color represents the number of people for which the methodology is suited. Crystal Clear is the lightest color and is meant for the smallest project groups, of two to eight people. Darker colors are for larger groups.

Unlike traditional thick methodologies, as PRINCE2 is, Cristal Clear is flexible as to what project teams are supposed to do and how to do it. This is expressed in the properties over technique and stretch to fit principles. In fact, Crystal Clear is designed to be usable for as many project groups as possible, with the least number of new techniques to learn.

One of Crystal Clear's major strengths is also its principal disadvantage: it tries to be a methodology that is applicable in as many cases as possible, which prevents it from ever being the "best" methodology in any specific case.
The Rational Unified Process (RUP) was acquired by IBM in 2003. It is a thick methodology, which means that the whole design process is described highly detailed. Thus, it is applicable mostly on larger projects. Unified Modeling Language (UML) easily adapts the methodology to the needs of a various projects or companies. In RUP, an iterative approach is used unlike a Waterfall approach. It means that the phases of requirements, analysis, design, implementation, integration and testing, are not done in strict sequence. Each iteration includes some, or most, of the development disciplines (Kroll \& Maclsaac, 2006).

This iterative approach leads to higher efficiency. Testing takes place in each iteration, not just at the end of the project life cycle. Thus, problems are noticed earlier, and are therefore easier and cheaper to resolve. When using waterfall approach, it can happen that some project members have to wait for the completion of a pervious phase before they start their iteration cycle. Using an iterative approach solves this problem. Integration and implementation will happen not only at the end of the project, but in each iteration. This saves time, since more team members can work more of the time.

RUP is a commercial product that it is not open and it has to be bought from IBM. It is a very complex methodology, sometimes difficult to comprehend for both project managers and project members. For successful implementation, every participant in the project has to learn working with RUP. Therefore, it is not the most appropriate methodology for most small projects.

Project in controlled environment (PRINCE2) is a process-based methodology for effective project management, used in the private and public sector (Barker, 2013). It is a structured approach to project management and provides a method for managing projects within a clearly defined framework. PRINCE2 describes procedures for coordinating people and activities in a project, for designing and supervising the project, and envisage the activities in case the project does not develop as planned and it has to be adjusted. In this method, each process is specified with its key inputs and outputs and with specific goals and activities, which has to be carried out, which gives 
an automatic control of any deviations from the plan.

PRINCE2 provides a common language for all participants in the project. The various management roles and responsibilities involved in a project are fully described and are adaptable to suit the complexity of the project and skills of the organization.

Besides the key concepts of PRINCE2, there are some other advantages of its use. It is a standard methodology providing organizations with a standard approach to the management projects. The methodology embodies proven and established best-practice in project management. It is widely recognized and understood, and so provides a common language for all participants of the project. PRINCE2 is very useful for educative use. It enables project to have a controlled and organized start, middle and end, regular reviews of progress against plan, flexible decision point, the involvement of management and stakeholders at the right time and place during the project, as well as good communication channels between the project, project management and the rest of the organization.

Every project member should be quite familiar with every aspect of PRINCE2, which can be consider as a disadvantage of this methodology. It is very expensive to give everyone involved a course to study PRINCE2. A lot of documents and lists have to be written, and because project managers only have to inform project board about the status of the project, when something goes wrong they can easily blame others. Splitting up a PRINCE2 project often results in a lack of knowledge of the project by responsible persons, like the project manager.

In the Waterfall methodology, development phases happen sequentially. The progress is seen as flowing steadily downwards like a waterfall through the phases of conception, initiation, analysis, design, construction, testing, implementation and maintenance. One of the differences between Agile and waterfall methods is that testing of the software is conducted at different stages during the software development lifecycle. In the Waterfall model, there is always a separate, testing phase near the completion of an implementation phase. However, in the Agile model, testing is usually done concurrently with coding, or at least, testing jobs starts in early iterations.

Every project is different and therefore demands a different approach. When the demands are clear and stable, it is reasonable to choose a waterfall approach. When large dynamics and software with a high degree of interactivity are involved, then it is more appropriate to choose the Agile method.

\section{RESEARCH METHODS}

The survey was conducted in November 2013 among companies in Republic of Macedonia. For the data collection activity, a specific questionnaire was designed. The target group consisted of different types of companies. The questionnaire objective was to collect information about the respondents' and their awareness regarding implementation of project management methodologies. Another objective was to investigate the user satisfaction with respect to specific project management method implementation. The questionnaire surveyed tools and techniques in use, their benefits, as well as the level of success of projects within the organizations with respect to the project parameters, such as time, cost and quality.

The data collected was analyzed and is represented graphically in this paper by considering the percentages.

\section{SURVEY RESULTS}

The data from the questionnaire were used to determine the following issues:

- organization profile (the number of employees, years of existence, type, etc.)

- IT project implementation,

- project management in IT project implementation,

- awareness of the existence of project management methods and tools in use,

- benefits of project management implementation in IT project.

- According to the results, 30 of 36 surveyed organizations (83\%), have either 50 to 250 
employees, or more than 250 employees.

Only 2 of them have less than 10 employees, and 4 have up to 50 employees, as it is shown in the Fig. 1.

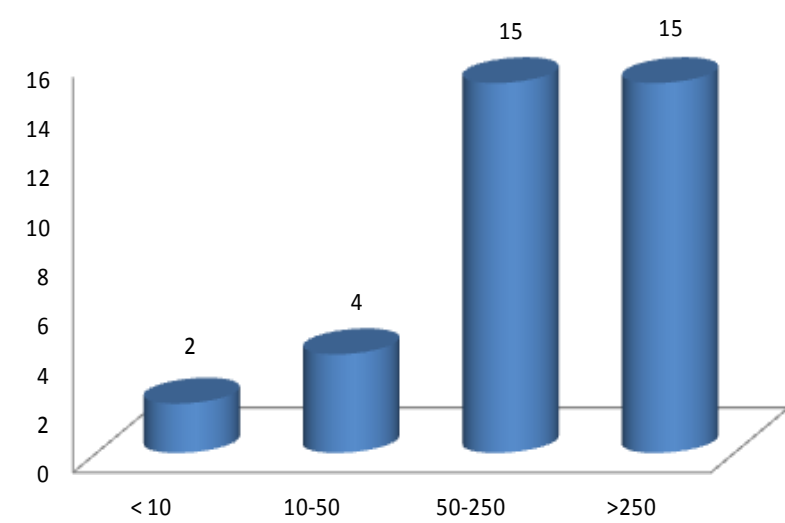

Fig. 1 Number of employees

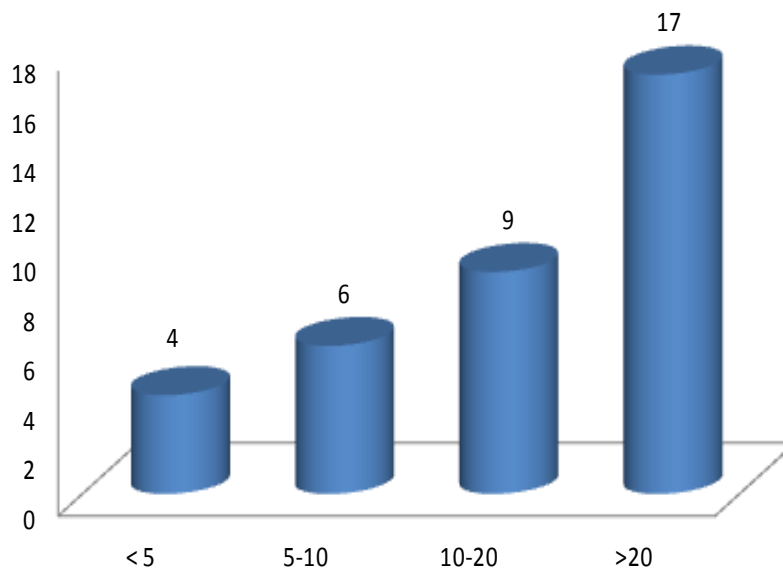

Fig. 2 Period of organization existence
Almost half of surveyed organizations (47\%) exist more than 20 years, while $25 \%$ exist between 10 and 20 years, which is relatively long period, having in mind that Macedonia exists as an independent country since 1991 (see Fig.2).

The survey was conducted in different types of organizations like companies, banks, schools, insurance companies etc. 11 of the surveyed organizations were companies.

The educational, administrative and financial institutions, were equally represented (by 8 of each type), as it is shown in Fig. 3.

The second set of questions was about implementation of Information and Communication Technologies projects.

The results show that $86 \%$ of respondents use IT. Only $8 \%$ never applied IT, and does not intend to do it, while the remaining $6 \%$ intend to apply IT in the future.

This result is certainly a good indicator for the organizations, since it shows increasing awareness of the usefulness of technologies application for improving processes and facilitating the work of the organization.

About $92 \%$ of the companies believe that business strategy can easily be implemented through the use of ICT systems, while only $8 \%$ are not sure of it. No organization responded that ICT do not help in the implementation of business strategy.

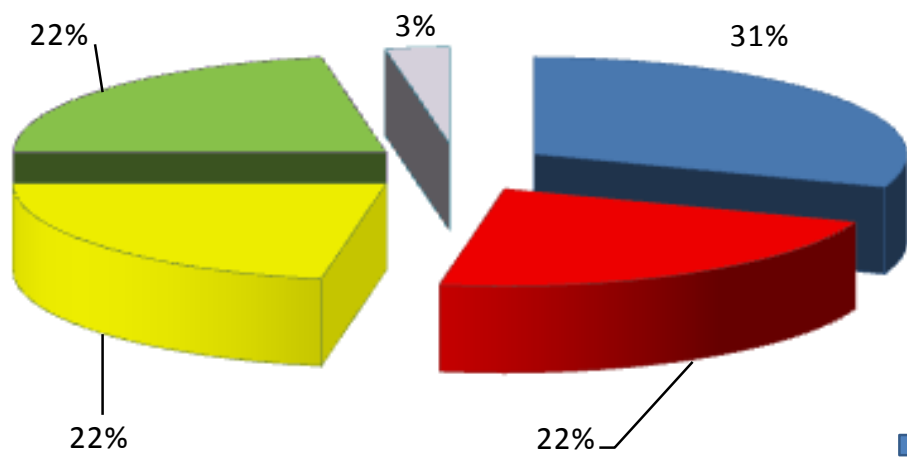

Company

Educational institution

$\square$ Administrative institution

$\square$ Financial institution

$\square$ Other

Fig. 3. Type of the organization 
Gegovska-Zajkova S. Organizational strategy and management methods MEST Journal Vol. 3 No. 1 pp. 21-29

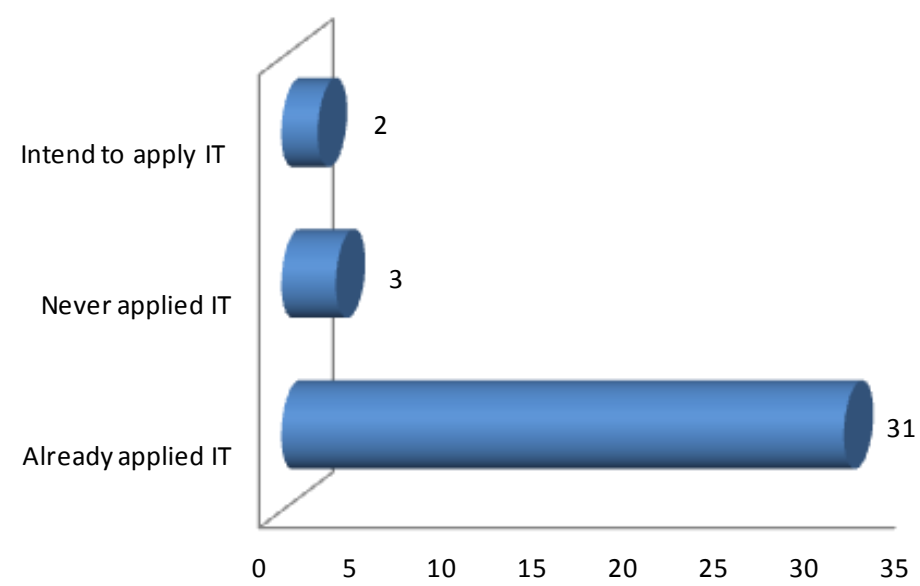

Fig. 4. Implementation of ICT in the organizations

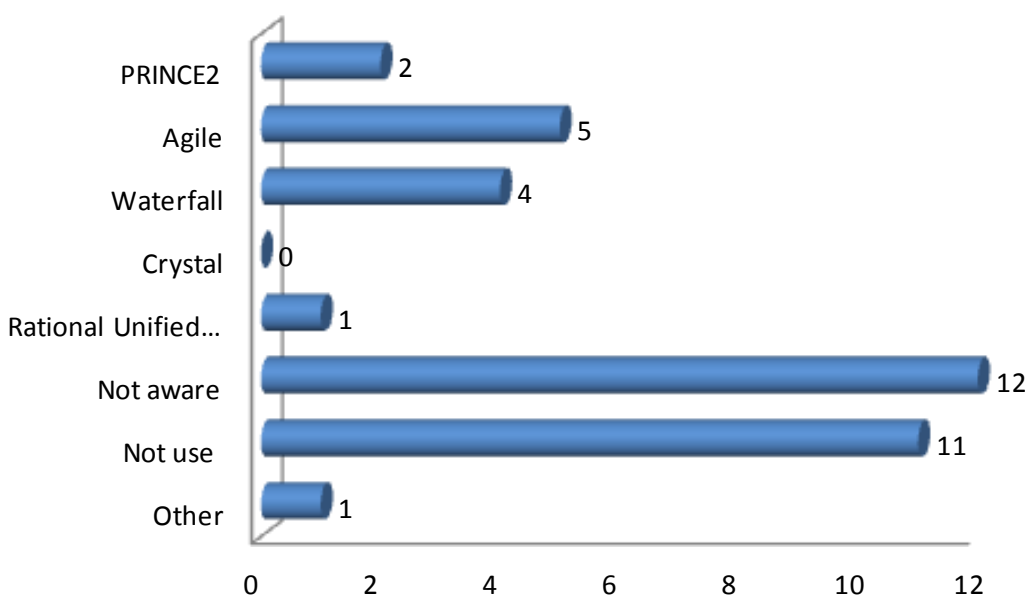

Fig. 5. Implementation of project management methods

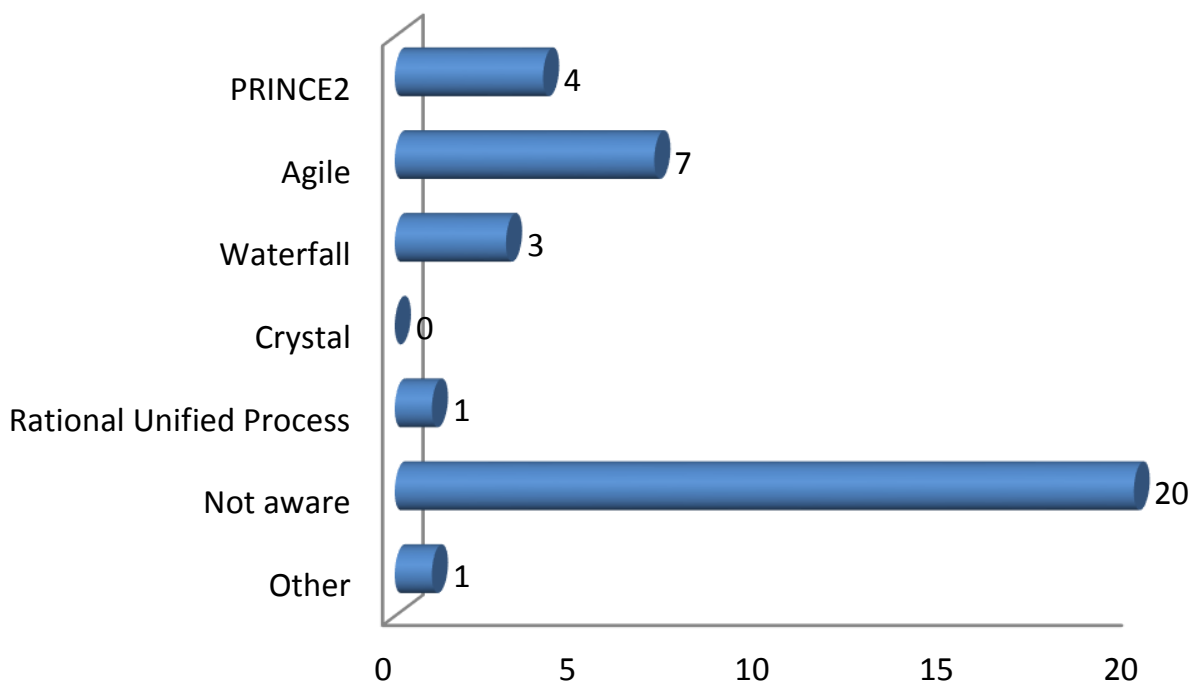

Fig. 6. Ranking the best project management methods 
The final set of questions concerned the application of project management in the implementation of ICT projects. The results show that $53 \%$ of respondents apply project management in the implementation of ICT. More than a quarter of respondents (28\%) are not familiar with project management at all, while $19 \%$ have no answer.

Surprisingly, more than half of the respondents either do not use (31\%), or are not familiar (33\%) with application of any project management methodology of in their organization. The most popular project management methods, as it is shown in Fig. 5, are Agile methodologies (16\%), followed by Waterfall model (13\%). Two organizations implement PRINCE2 (5\%), while the Rational Unified Process (RUP) is used in only one organization (3\%). There is also one organization that did not implement project management methods, but use external services. About $56 \%$ of the respondents did not know which method is the best for a successful implementation of ICT projects. $19 \%$ of them believe that Agile methods are the best, followed by PRINCE2 (11\%), Waterfall method (8\%) and the Rational Unified Process (3\%). The rest $3 \%$ of the organizations, believe that it cannot be clearly determined which method is the best (see Fig. 6).

They also believe that it would be the most appropriate to use a combination of few methods, or integrate the best practices, which are adapted to the needs and processes in the company.

The last question concerns the respondents' opinion about the benefits from the application of project management in the implementation of ICT projects. According to the survey results, the majority of respondents believe that the greatest benefit is meeting the prescribed time frame and budget of the project. Application of project management provides: control over the project at any time, control of the project flow, which facilitates the design of deadlines, resources management and general coordination and organization of the project. No less important benefit is dealing with risks in the project, which eventually brings higher quality of services and projects.
Some respondents stated that the application of project management achieves higher reliability, increases data security, increases competitiveness and better services.

In general, all respondents believe that applying project management methods offer greater efficiency and more rational use of resources in the projects. It improves communication between stakeholders in the project and in a presence of any change of the schedule, it enables easy implementation of the Agile method.

Another benefit that was pointed out is the documentation of the project. This experience can be very useful for future projects. The implementation of project management results in better effectiveness and efficiency in the projects, leading eventually to a successful project.

\section{ANALYSIS OF THE RESULTS}

Analysis of the answers shows that all state institutions use ICT projects, but only half of them apply project management methods in their implementation. They typically use Agile methodologies and PRINCE2 method.

Almost all companies implement ICT projects. Most of them apply project management and its methods. The most commonly used is Waterfall model, followed by Agile methods. Some companies find that the best solution is a combination of PRINCE2, Agile and Waterfall. All respondents believe that it helps or will help in meeting their business strategy.

Only one of eight surveyed educational institutions use ICT in their work and none of them are familiar with project management and its methods, although most of them suppose that using ICT it would help their business strategy.

The banks are implementing ICT projects, but only part of them applies specific project management methodology, such as RUP, Waterfall and Agile. They think that application of project management methodology would lead to a better organization of the work within the planned parameters, greater control and also more successful projects.

The main reasons for the failure of the projects are as follow: unexpected new demands from clients, poor communication between team members (working on the project) and between users and key stakeholders. Furthermore, the following 
issues could be added: not clearly defined requirements, the alignment of business processes and management's strategy requirements and excessive costs of scope of works. In the beginning of the project, one of the important problems is the lack of in-depth analysis of requirements, design, as well as a selection and hiring the best employees that have appropriate skills for project implementation. Since there is no proper analysis in advance by end users, very often there is a problem in the selection of tools and methods that correspond with their real business processes.

The analysis of the questionnaire answers shows that only half of the organizations in the Republic of Macedonia applied project management methods. The other half is not familiar with the methods and techniques and their application. In the companies that apply project management, the most popular are Agile methodologies. According to the answers, the companies believe that it is the best methodology to be used, but the implementation depends on the type of project and its complexity. The use of project management software is very important in the application of project management portfolio, since it significantly facilitates the successful work of project managers.

Although only a half of the organizations in the Republic of Macedonia applied project management methods, it is our opinion that some internal guidelines exist, so that new entrants to the organization can at least follow the relevant procedures. This perception was not explicitly measured by our survey. We suppose that some reasons for the absence of a formal methodology include, among others, the limitation of time allocated for completion of a project, as well as lack of employees' appropriate training regarding software project management. (Louws, 2008)

From the survey data it seems that the use of a project management methodology emphasizes quality management versus cost management. Planning and procurement management are also well represented, followed by human resource management, communications management and risk management. It is, however, possible that human resource management, communications management and risk management are addressed separately, rather than by the methodology employed, although grouping all these tasks would be helpful.

The information gathered from the questionnaires, after analysis, reveals that project managers are not entirely comfortable with the methodologies in use, given that the latter does not appear to yield expected success rates.

\section{CONCLUSIONS}

According to the survey results, we can conclude that most of the organizations are aware of the benefits of ICT in the implementation of business strategy and they apply them to facilitate the business processes in the organization. But many projects, even in the more developed countries in the European Union (McManus \& Wood-Harper, 2008), failed and did not achieve the desired goals. As it was already concluded in the analysis, the main reasons for the failure of the projects are changes in project scope and communication between the key stakeholders participating in a particular project.

Some of the developing countries usually have to face with a shortage of skilled staff, difficult economic and social conditions and turbulent political situation, which could be the reasons of limited implementation of project management methods and technique. The awareness of the necessity to maintain-up and apply project management knowledge, skills and technique, should be an objective for the top managers in the Age of the New Economy.

\section{Works Cited}

Barker, S. (2013). Brilliant PRINCE2: What You Really Need to Know About PRINCE2. Pearson.

Cockburn, A. (2004). Crystal Clear: A Human-Powerd Methodology for Small Teams. Addison Wesley Pearson Education.

Dijk, A. J. (2009). Success and Failure Factors in ICT Projects. School of Engineering and Information Sciences, Middlesex University, Hendon, London.

Grant, R. (2002). Contemporary Strategy Analysis. Blackwell Publishing. 
Kroll, P., \& Maclsaac, B. (2006). Agility and Discipline Made Easy: Practices from OpenUP and RUP. Michigen: Addison-Wesley.

Louws. (2008). Projectmanager Agile moet vooral coachen. Computable, No. 43.

McManus, J., \& Wood-Harper, T. (2008, September 10). A study in project failure. Project Management, http://www.bcs.org/content/ConWebDoc/19584.

Received for publication: $\quad 11.02 .2014$

Revision received: $\quad 29.07 .2014$

Accepted for publication: $\quad 11.08 .2014$

\section{How to cite this article?}

Style - APA Sixth Edition:

Gegovska-Zajkova, S., Rogleva, N. K., \& Fustic, V. (2015, Jan 15). The alignment of the organizational business strategy and project management methods. (Z. Čekerevac, Ed.) MEST Journal, 3(1), 21-29. doi:10.12709/mest.03.03.01.03

Style - Chicago Fifteenth Edition:

Gegovska-Zajkova, Sonja, Nevenka Kiteva Rogleva, and Vangel Fustic. 2015. "The alignment of the organizational business strategy and project management methods." Edited by Zoran Čekerevac. MEST Journal (MESTE) 3 (1): 21-29. doi:10.12709/mest.03.03.01.03.

Style - GOST Name Sort:

Gegovska-Zajkova Sonja, Rogleva Nevenka Kiteva and Fustic Vangel The alignment of the organizational business strategy and project management methods [Journal] // MEST Journal / ed. Čekerevac Zoran. - Belgrade : MESTE, Jan 15, 2015. - 1 : Vol. 3. - pp. 21-29.

Style - Harvard Anglia:

Gegovska-Zajkova, S., Rogleva, N. K. \& Fustic, V., 2015. The alignment of the organizational business strategy and project management methods. MEST Journal, 15 Jan, 3(1), pp. 21-29.

Style - ISO 690 Numerical Reference:

The alignment of the organizational business strategy and project management methods. GegovskaZajkova, Sonja, Rogleva, Nevenka Kiteva and Fustic, Vangel. [ed.] Zoran Čekerevac. 1, Belgrade : MESTE, Jan 15, 2015, MEST Journal, Vol. 3, pp. 21-29. 